\title{
The World of Penguins: The Role of Peer Culture in Young Children's Interaction in Online Games
}

\author{
Tolga Kargin
}

\begin{abstract}
In this study, to be able to understand the role of the children's interactions with each other and the role of online and offline communities on children's play and digital literacy practices, we examined a group of children's collaborative play within the Club Penguin virtual world while they were engaging in an after-school setting. We had eight participants (one girl and seven boys) between 5-8 years old. During our study, the participants worked independently, but sat side by side in the computer room as they controlled their penguin avatars in the virtual world. To answer the central research questions, we used several kinds of data collection methods. We performed participant observations, took fieldnotes, and videotaped all 6 one-hour-long sessions during our study. Since we focus particularly on the interactions among children and their effects on play and literacy practices, we employed Vygotsky's Zone of Proximal Development (ZPD) concept as our theoretical framework. Also, to be able to analyze the influence of children's online and offline communities on their play and digital literacy practices, we used the second-generation activity theory.
\end{abstract}

\section{Introduction}

According to North Central Regional Educational Laboratory (NCREL), "digital-age literacy" is one of the most relevant twenty-first century skills (Trespalacios, Chamberlin, \& Gallagher, 2011, p. 49). Twenty-first-century children should be able to organize, understand, analyze, and evaluate information by using digital technology. As Stephens and Ballast (2010) point out, today's children use digital platforms more than any previous generation. They are reading, writing, shopping, communicating, and playing with each other on digital platforms. They are rarely practicing digital literacy in schools, but mostly using them in their homes and in after-school settings.

Today's children are growing up in the digital age, so technology is a significant part of their lives. Prensky (2006) defines twenty-first-century children as "Digital Natives - the new 'native speakers' of the digital language of computers, video games, and the Internet" (p. 28). Our children, live within technology and use technology very frequently in their daily lives. Therefore, their literacy practices are different from those of previous generations. The relationships between peer cultures and the digital literacy practices of adolescents and young adults have been heavily researched (Black \& Steinkuehler, 2009). However, far less attention has focused on emergent readers' and writers' digital literacy practices in virtual worlds 
such as Club Penguin. The purpose of this study is to examine how young children use play and digital literacy practices in order to be able to participate in their online peer culture, and what the roles are of the online and offline communities to which they belong.

This study is a part of an ongoing project conducted by Karen Wohlwend and her research team. In this part of the project, I gathered data and analyzed it as a coinvestigator. In this study, we examined the collaborative play of a group of children within the Club Penguin (Disney) ${ }^{1}$ virtual world while they were participating in an after-school program. To be able to understand the role of the children's interactions with each other and the role of online and offline communities on children's play and digital literacy practices, we attempted to answer the following central research questions:

- How do young children interact with each other in after-school settings while playing online games on popular media websites and social networks?

- What is the role of these online and offline settings on children's interactions?

\section{Access to Technology: Experts and Novices}

According to the October 2010 report of the United States Census Bureau, 79.2\% of 3-17 year old children live in households with Internet access, and $56.2 \%$ of this age group have individual access to it at home. Therefore, even though children in this age group live in households with Internet, this does not guarantee their individual access to it. In addition, even though they say they have individual access and use it at home, it is hard to figure out from this report at what level and for what purposes they use it.

According to Warschauer (2008), there is enormous diversity among children in terms of their access to technology. Warschauer analyzes access to technology under four general areas: physical, digital, human, and social resources. Physical resources are the necessary devices (e.g., computers or mobile devices), and the Internet connection. Digital resources refers to content that is available online; even though there is an unlimited information that individuals can reach online, this information is limited to the individuals' culture, and their language ability. Human resources refer to the knowledge and skills required to use computers and the Internet. These skills include both the ability to read and write, and digital literacy. Finally, social resources refer to social relations and the social structure in families and communities. According to Warschauer, "there are many degrees of access to ICT [Information and Communication Technology], depending on a complex combination of physical, digital, human, and social resources available" (p. 144).

\footnotetext{
${ }^{1}$ Club Penguin (Disney) is a virtual world containing different kinds of online role-playing games and activities where players are represented by penguin avatars.
} 
To be able to answer our central research questions, first we need to identify our participants' degree of access to technology. With respect to Warschauer's definition of access to technology, there was considerable diversity among them. In terms of physical resources, as was noted in our field notes several times, and easily determined from conversations between participants, some of them had been using their own computers and the Internet at home for years, but some others only had access to technology at school and in the after-school setting.

There was a divide among the participants in terms of human resources, too. While some of them are experts on the Club Penguin game or at using computers, others are novices with little (if any) experience. While deciding on their expertise, we controlled for whether the participants had attended previous computer room clubs, or if they have their own Club Penguin accounts. The participants we labeled as novices are the ones who struggle to find letters on the keyboard, or who have a hard time opening a webpage.

In Warschauer's definition, social resources refer to social relations and social structures in families and communities. Since we had a diverse participant group in terms of their races, their social resources were also different from each other. In respect to Warshauer's definition of access to technology, there was diversity among the participants of our study. However, this did not affect our study negatively. Since the participants sat side by side in the computer room and played the same game, they answered other participants' questions and helped and taught each other during the study.

\section{Theoretical Framework}

Since we focus particularly on the interactions among children and their effects on play and literacy practices, we decided to use Vygotsky's Zone of Proximal Development (ZPD) concept as our theoretical framework. As broadly explained by Vygotsky (1978), the Zone of Proximal Development "is the distance between the actual developmental level as determined by independent problem solving and the level of potential development as determined through problem solving under adult guidance or in collaboration with more capable peers" (p. 86). Vygotsky highlights the importance of peer teaching with the idea of the Zone of Proximal Development, which was central to our study.

Current Vygotskian scholars (Goncu and Becker, 1992) believe that in addition to learning from a more knowledgeable peer, the activity itself can create a Zone of Proximal Development for children. For example, when children interact with an online game, their interaction with physical and visual tools creates a zone for children within which they learn how to play the game.

For our second question, to be able to analyze the influence of children's online and offline communities on their play and digital literacy practices, we used second-generation activity theory (Engestrom, 1987). In second-generation activity theory, the importance of interaction among individuals becomes more visible. The division of labor, the rules in the community, and the community itself are the 
important components. The roles of the each components of second-generation activity theory are discussed throughout this paper while analyzing our data.

\section{Methods}

\section{Setting/Participants}

For an after-school setting we chose the Boys and Girls Club, ${ }^{2}$ which serves mostly working- and middle-class families in a small town in the Midwestern US. The Boys' and Girls' Club offers small group clubs organized around children's interests. While some participants play musical instruments, some play in the gym, some read books, and still others do homework. Within the Boys' and Girls' Club, children are divided into three groups: eight and youngers, nine and olders, and teens.

We studied the eight and youngers in a computer room club. As an online game for our study, we chose the Club Penguin game designed by Disney, and entitled our club the "Club Penguin Club." We intentionally chose the Club Penguin game, because this game allows players to see each other on screen; the children are able to see each other, chat with each other, and play together in real time. In our project, this feature helped children enrich their interactions in both the online and offline settings.

Club Penguin has basic and deluxe membership options. The basic level is a free membership for everyone who registers and provides an email address. The members can change their avatar's name and color, and can get a basic igloo. The deluxe membership is $\$ 6.99$ per month and allows members to buy additional clothes for their avatars, and furniture and artifacts for their igloos. The members who have deluxe membership can also attend the members-only events, go to the secret places, and adopt pets (puffles). These features of deluxe membership offer members a greater amount of social capital (Marsh, 2011).

We had eight participants (one girl and seven boys) between 5-8 years old. During our club activities, the participants worked independently, but sat side by side in the computer room as they controlled their penguin avatars in the virtual world. The club met for one hour once a week for six sessions on Wednesday evenings from 5:00 p.m. until 6:00 p.m. Leaving or staying in the room was totally up to the participants. We did not ask them to stay in the room if they wanted to leave. Sometimes, they were simply bored and left the room, sometimes our club time overlapped with other activities and they chose to attend the other activity, and sometimes their parents came earlier and picked them up to go to home. During the six sessions, we observed whichever participants we had in the computer room: sometimes it was all eight of them, and sometimes it was only a few of them.

\section{Data Collection}

This research study uses ethnographic methods (Ericson, 1990) to examine children's online and offline interactions within the Club Penguin virtual world

${ }^{2}$ Boys and Girls Clubs are after-school settings where young people go to learn, do homework, develop socials skills, express themselves creatively, and participate in sports. 
while they play in the Boys' and Girls' Club computer room. To answer the central research questions, several kinds of data collection methods were used. We performed participant observations (Ericson, 1990), took field notes, and videotaped all six sessions during our study.

\section{Field Notes and Observation}

During the initial visit, the computer room rules and the names and assigned penguin accounts of each participant were recorded. During the initial and subsequent visits, I recorded the participants' seating plans (see Appendix 1) and their participation schedule. I also recorded the interaction of the participants, who were sitting on the computers in front of the cameras. I watched their play, asked them questions while they were playing, and recorded their answers.

\section{Videotaping}

During club activities, we provided the participants with precreated penguin accounts but also allowed them to use their own account if they wanted to. We chose two computers, which are located side by side, and videotaped just those two computers with the help of three cameras. In each session, the participants sat on these two computers on a first-come-first-serve basis, and we set three cameras (left-middle-right) to capture the interaction between the participants more clearly. The left and right cameras captured the screens of the players. The middle camera had a wider angle and captured both of the screens and the physical interaction between players. While analyzing our video records, we synchronized those three cameras. This helped us to hear players' conversations better. The left and right cameras helped us to see the online interaction between the penguin avatars, and the middle camera helped us to analyze the physical interaction between the players.

\section{Findings}

The participants we observed in the Boys' and Girls' Club had different cultural backgrounds; they came from different families and each of them had their own social history. They were using computers and online video games at different levels, according to their expertise. Some of the children were familiar with the Boys' and Girls' Club atmosphere and were proficient at the online games, and some were novices and needed their more knowledgeable peers to help them learn the rules of both the Boys' and Girls' Club computer room and the online game. The interaction between the expert and novice children in this study reminded us of Vygotsky's (1978) Zone of Proximal Development (ZPD), because students were teaching and learning from one another constantly.

In our study, our novice club members had the opportunity to work with proficient club members. Expert and novice members were engaged in the Club Penguin game and learning from each other. An early instance comes from my field notes from the very first day of our study. We had written the user name and password of the penguin accounts on sticky notes and attached them to computers 
on the very first day of our study, but didn't explain to the club members how to log into the game. Jack, our novice player, tried several times to log into the game on his own, but he couldn't. Karl, a proficient player sitting at the next computer, explained to Jack where he needed to type the user name and password. Since Jack did not understand what Karl said, Karl grabbed Jack's keyboard and showed him how to log in. After a while, Jack's computer froze, and he had to log into the game again. Karl took Jack's keyboard and typed the user name and the password, but he could not $\log$ in because he had made a spelling error. Jack figured out what was wrong and corrected the mistake, and logged into the game on his own.

According to Vygotsky (1978), the things children do today with the help of more knowledgeable others within the Zone of Proximal Development will be the things they do on their own tomorrow. At the beginning, Jack was unable to log into the game; he tried several times, but failed. After his proficient partner Karl demonstrated to him how to $\log$ in, Jack learned how to do it. When he needed to log into the game, he could do it on his own. This example clearly demonstrates Vygotsky's concept of the Zone of Proximal Development, but when we look at our overall data, we have very limited proficient-novice interaction as in this example. So proficient-to-novice peer teaching appears to be an exception in our study.

However, while Chaiklin (2003) criticizes the common conception of the Zone of Proximal Development, he mentions that we should not focus on particular tasks to analyze it, because it is not necessarily a single task. Instead, we should analyze the role of the Zone of Proximal Development in terms of the child's general development. When we compare the video records of the first week and the final week, it is clear that our members had learned how to play the game, how to earn more coins, how to become friends with other penguins, and how to send messages to each other. For example Jack, our novice player who struggled to log into the game in the first week, earned hundreds of coins from several games, earned a yellow belt from DoJo fights, made seventeen penguin friends, learned how to send a message and how to read incoming messages, and became a proficient player by the end of the last session. According to Chaiklin's assertion, children's interaction within the game helped them to develop themselves within their Zone of Proximal Development.

To more clearly explain the role of the Zone of Proximal Development in this learning process, we can also focus on how Vygotsky's (1978) notion of mediated action explains it. Vygotsky's original version of a culturally mediated act includes the stimulus (S)-Response (R) connection (p. 40). However, the reformulated version of the model from the first generation of activity theory is the triad of Subject, Object, and Mediating Artifact (Engestrom, 2001, p. 134). As shown in Figure 1, the subjects in our example are the Club Penguin Club participants who are playing the game and having fun. The mediating artifacts are the computer, the Club Penguin virtual world, and their play partners. Our participants (Subjects) are interacting with these mediating artifacts to play the game and have fun. The object in our study is playing the Club Penguin game and having fun. As an outcome, the 
participants learned how to play the game, and gained experience with several digital literacy practices.

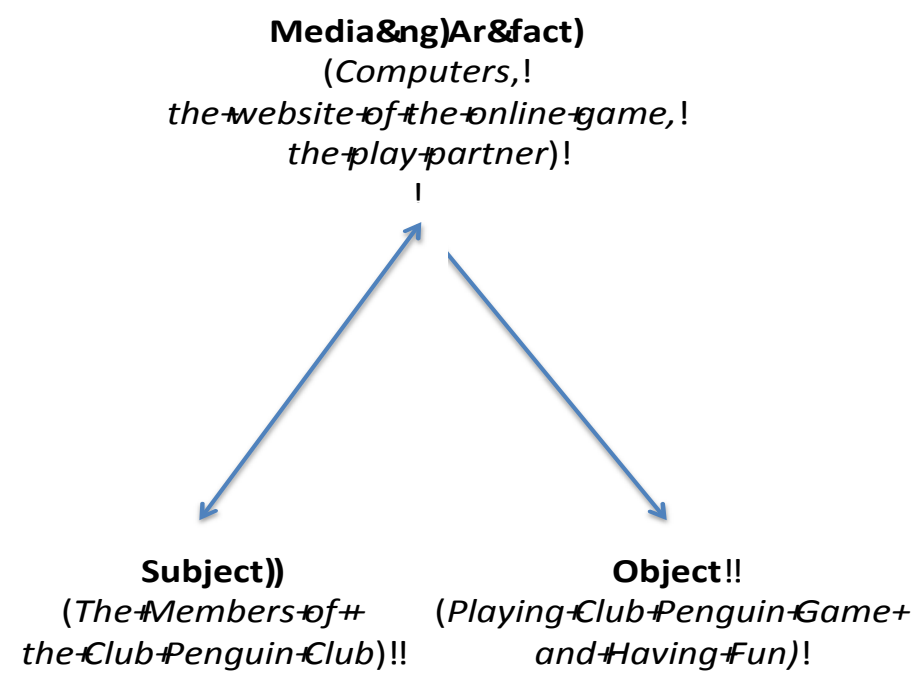

Figure 1. First-Generation of Activity Theory Triad

As cited by Matusov and Hayes (2000), Goncu and Becker (1992) correctly highlight that "not only a more capable partner in a joint activity but also the activity itself can produce a Zone of Proximal Development for a child" (p. 200). In our study, there was a dyadic interaction between the members and the mediating artifacts: our participants were using these mediating artifacts (see Figure 1) to be able to play the game, and their trials and their play partners' demonstrations helped them reshape their ideas about playing the game. This activity system created a Zone of Proximal Development for the participants. The outcome was that they learned how to play the game and experienced the digital literacy practices within the Zone of Proximal Development created by the activity.

To be able to examine the participants' digital literacy practices and their interaction in online and offline settings, we selected a five-minute video clip from our video records. In choosing this video clip, we followed three steps. First, we coded the transcripts of our video records according to the location and the game our participants played. We selected the ones in which both partners play the same game in the same location. Then we looked for the ones that have peer mediation. The ones with powerful interactions between the partners were selected. Finally among those videos we chose the one with novice-to-novice interaction.

In this video clip, our participants, Katherine and Chris, were sending friend requests to other penguins in order to increase their friend number, sending messages to other penguins, and playing games in the same virtual place, called Mine. Even though the Club Penguin offers ways to make meaning through penguin actions and accessories, and has been designed with much less print compared to 
other virtual worlds (Marsh, 2010; Grimes, 2010), we realized that even in this short time period, the participants engaged in several digital literacy practices (Table 1). From our analysis, we came up with a list of digital literacy practices. They were reading silently, reading orally to share their ideas with their partner, and reading aloud to themselves. They were sending prewritten messages to other penguins and rereading their own writings (Picture 1). Also, while playing, they were acting physically: they were using the arrow buttons and space button, and clicking and hovering with the mouse.

\begin{tabular}{|c|c|c|c|c|}
\hline \multirow{2}{*}{\multicolumn{3}{|c|}{$\begin{array}{c}\text { Literacy Practices: Reading, Selecting } \\
\text { Prewritten Messages, } \\
\text { Technology/Gaming }\end{array}$}} & \multicolumn{2}{|c|}{ Frequency* } \\
\hline & & & Katherine & Chris \\
\hline \multirow{8}{*}{ 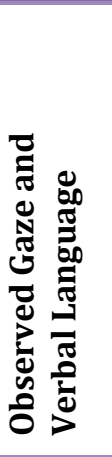 } & & Searching & 38 & 24 \\
\hline & & Reading Silently & 17 & 9 \\
\hline & & Partner Reading & 4 & 3 \\
\hline & & Reading Aloud to Self & 4 & 0 \\
\hline & & Retelling & 2 & 1 \\
\hline & & Rereading Own Writing & 1 & 0 \\
\hline & & Selecting / Confirming & 13 & 16 \\
\hline & & Talking & 3 & 0 \\
\hline \multirow{4}{*}{ 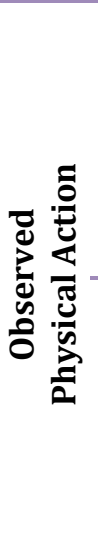 } & \multirow{2}{*}{ 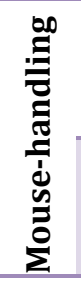 } & Clicking & 12 & 9 \\
\hline & & Hovering & 22 & 8 \\
\hline & \multirow{2}{*}{ 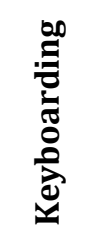 } & Space Bar & 1 & 2 \\
\hline & & Numeric Pad / Arrow Keys & 1 & 51 \\
\hline
\end{tabular}

Figure 1. Digital Literacy Practices

Searching: 1 click that opens a pop-up or drop-down menu.

Reading Silently: Looking at a written word/phrase for a couple of seconds. Partner Reading: Reading orally to share ideas.

Reading aloud to self: Inner speech

Retelling: Retelling the word he/she already read.

Rereading own writing: Retelling the word he/she has written/chosen.

Selecting/Confirming: Clicking on the secondary confirmation buttons (i.e., after sending a friend request, answering the following question: "Would you like to add ... to your friends? Yes/No")

Talking: Sending messages to and getting messages from the other penguins. Clicking: Clicking on the onscreen buttons to open options. 
Hovering: Hovering on the buttons to see drop-down menus.

Space Bar: Pressing the space bar.

Numeric pad (Arrow keys): Using arrow keys to move avatars in different games.

* Frequency gives the number of the particular actions/activities done by Katherine and Chris in the five-minute long video.

\section{Table 1. Digital Literacy Practices}

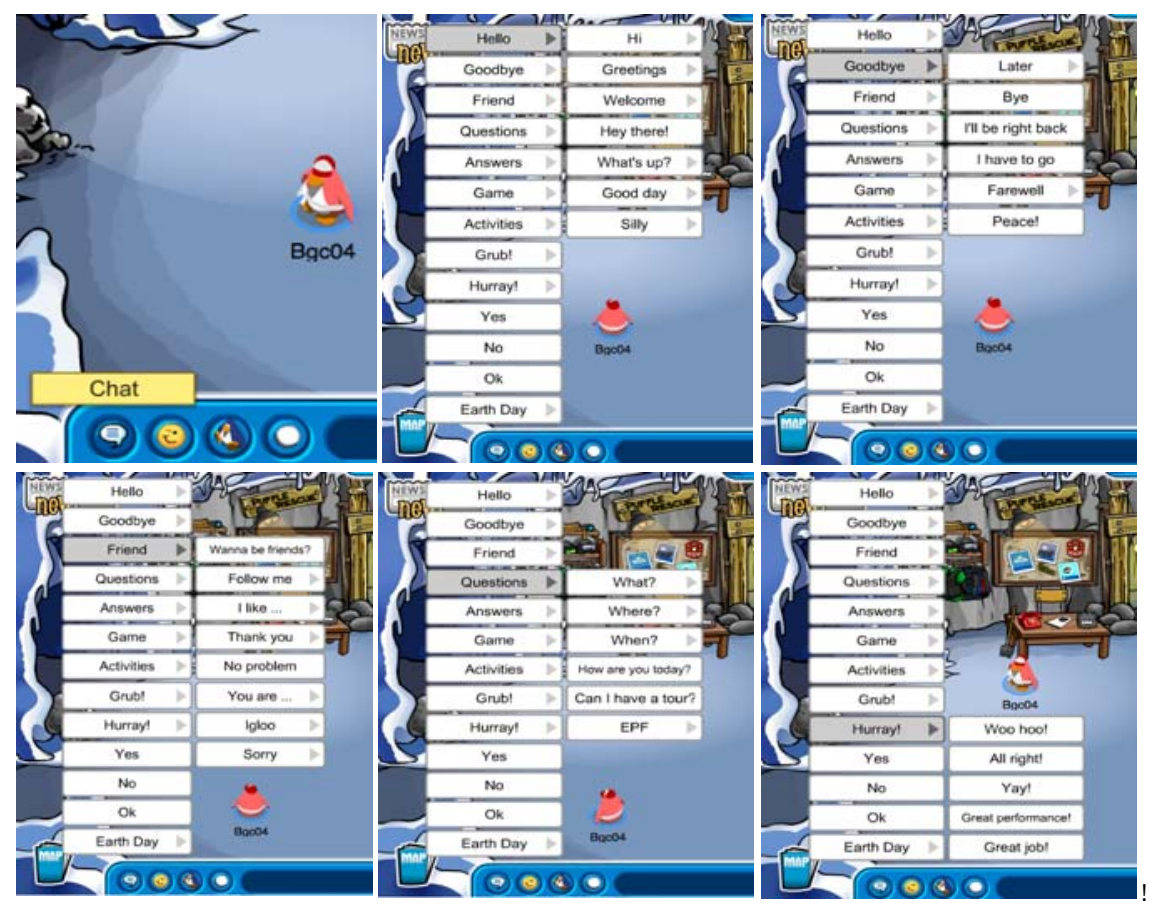

\section{Picture 1. Messaging}

Rowsell and Burke (2009) indicate that children's digital literacy practices with images and animations are quite different from their literacy practices with print materials. Children's interaction with mediating artifacts helps them in the meaning-making process. As children play in virtual worlds, they experience different mediated actions, such as clicking a mouse and using arrow keys on a keyboard in our case. Our particiants' digital literacy practices involve physical actions with those objects (e.g., moving a computer mouse and pressing keys on a keyboard), which mediated (Vygotsky, 1978; Wertsch, 1991) the activities in the Club Penguin virtual world (e.g., adding friends, chatting, scanning a map to find a location).

When we analyzed the video records, we realized that sometimes the participants were leading and following each other and simply copying the things their partner did while they were collecting coins in the Puffle Lunch game, recording their own music in $\mathrm{Dj} 3 \mathrm{~K}$, and fighting with other penguins in Dojo. They were watching their partner's game, learning the tricks of the game, and using those 
tricks in a different way in their own games. At first glance, it looks like simple copying. However, as first explained by Vygotsky (1987) and then highlighted by Chaiklin (2003), children can only imitate things that lie within their own Zone of Proximal Development. Children's interaction with this online virtual world and with their partners creates a Zone of Proximal Development for them, and they are able to copy the things that lie within this zone.

In order to answer our second central research question, "What is the role of the online and offline settings in children's interaction?", we decided to use the second-generation activity theory. In our study, children were playing the Club Penguin game in the computer room of the Boys' and Girls' Club in a small town in the Midwestern United States. There were eight members playing the same game at the same time in this computer room, and other players around the world were connected to the game online. The club participants shared the online and the offline space with other players, and there was interaction among the players in both the online and the offline settings. These conditions interface well with the second generation of activity theory (Engestrom, 1987). In the second generation of activity theory, Leont'ev highlighted the importance of the interaction between individuals in the activity (Cole \& Engestrom, 1993, p. 7). According to Leont'ev, division of labor, community, and the rules are the additional important components of the activity theory (Figure 2).

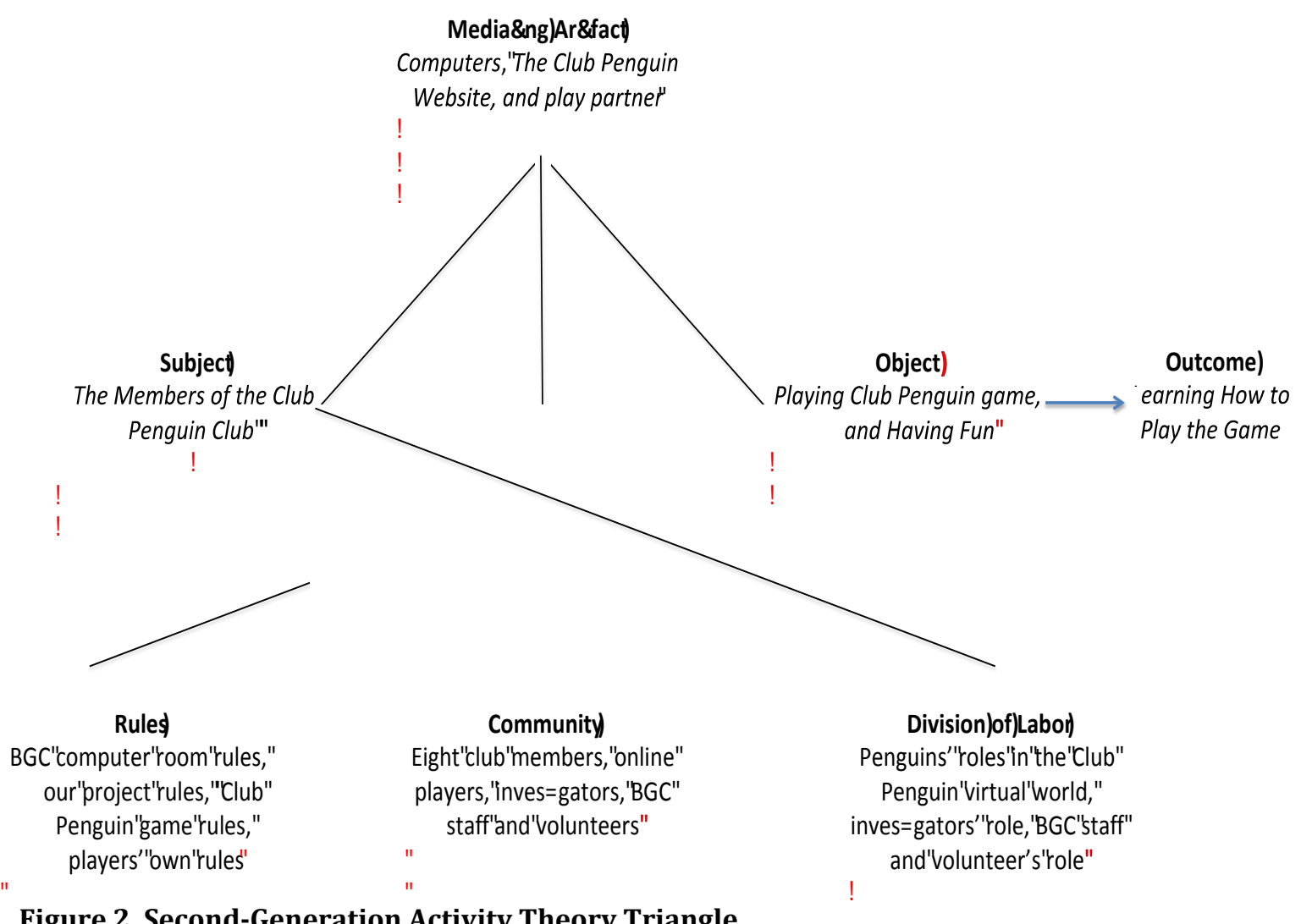

Figure 2. Second-Generation Activity Theory Triangle 
In our study, the club members had to consider the Boys' and Girls' Club computer room rules, our project rules, and the Club Penguin game rules when playing the game. In addition, the participants created additional game rules to be able to coordinate their play. These rules shaped the actions of the club members during the project. Their learning was also affected by the community in which they were situated. Additionally, the online community where they played together and the other club participants' contributions also affected the club participants' learning and play. The club participants were aware of the division of labor in the online and offline communities in which they were situated.

For our club participants, the aim of this activity was playing the Club Penguin game and having a good time while playing with each other. The game rules and the Boys' and Girls' Club computer room rules were effective components of this activity. For instance, to be able to see each other, the pairs had to log onto the same servers. Otherwise, even if they go to the same location and play the same game within the Club Penguin website, they are unable to see each other; they can only see the penguins who are in the same servers as them. This rule of the game limited the interactions between the pairs. Since the server that their partner had logged onto was full, some players could not log onto the same server as their partner. Thus, they could not see each other on screens, and could not play together. Play then became an individual activity, and the club participants' interaction and learning were negatively affected by this game rule.

Some of the Boys' and Girls' Club computer room rules also affected our club participants' play and digital literacy practices negatively. The Boy's and Girls' Club members are not allowed to chat with online players in any way. This rule limited our club participants' online interactions. Also, the Boys' and Girls Club members are not allowed to turn up the volume of the computers. Thus, our Club Penguin Club members could not play some of the games they wanted to, and this also negatively affected their interactions.

Community was the other important component of this activity. The club participants were interacting in both online and offline communities. They were in a computer room, and the other club members in the computer room affected their interaction. They were able to see where other club members went, what they did, and how they did. Then, the club members decided what to do in their own games. For example, after Chris heard other club members' voices from the back computers saying, "I am in the Pizza Place, I am in the Pizza Place," he turned back and told them, "Hey, I am going in the Pizza Place, too." The members in the computer room navigated each other to different locations in the game, and this increased their interaction within the online environment.

The other online participants who joined from all over the world were the second part of the community. The club participants were adding "foreign" penguins as friends. To be able to add fancy penguins as friends, our club participants would go to several locations and try to interact with different penguins. This also enriched their interaction, their digital literacy practices, and their learning. 
The club members were also aware of the division of labor in this activity system. They knew that they should play their game without bothering anyone else in the computer room; the computer room staff is responsible for everything in the room, so everyone should listen to the computer room staff; and the investigators are responsible for setting up the equipment and any questions related to the Club Penguin game. So, to be able to play the game, which is their purpose, they considered the division of labor; they asked general questions of the computer staff, they tried to not bother anyone else in the club, and they requested help from me for any issues they encountered in the game.

In sum, the club members have learned not only from the partners at whose side they were seated, but also from the online participants and other club members in the computer room. The game rules, the community rules, the division of labor, and the community itself were all effective components of this activity.

\section{Conclusion}

In this study, we analyzed our data using the lens of Vygotsky and activity theory. We realized that the club participants' aim was playing the game and having fun; they were not necessarily playing to learn something or practice digital literacy. However, while playing the game and having fun they learned how to play the game and experienced digital literacy practices. Besides interacting with more knowledgeable peers, their interaction with the Club Penguin virtual world created a Zone of Proximal Development for them, and they learned within this zone. Even the actions they simply copy from other participants fall within their Zone of Proximal Development, because children can only imitate things that lie within their zone. In this activity, in addition to the Club Penguin Virtual World and the play partners, the online and offline communities in which they are situated, the division of labor within these communities, and the rules of these communities have important roles.

It was clear that the participants had different backgrounds in terms of their access to technology. Some of the participants were novices and not familiar with the game, others were experts and had a rich knowledge of the game. We wonder if we divided them into two groups, novices and experts, and paired them as noviceto-novice, expert-to-expert, and novice-to-expert, if there would be any changes in their interactions, learning, and digital literacy practices. This question can be examined in a follow-up study. 


\section{References}

Black, R. W., \& Steinkuehler, C. (2009). Literacy in virtual worlds. In L. Christenbury, R. Bomer \& P. Smagorinsky (Eds.), The handbook of adolescent literacy research (pp. 271-286). New York: Guilford Press.

Chaiklin, S. (2003). The zone of proximal development in Vygotsky's analysis of learning and instruction. In A. Kozulin, B. Gindis, V. Ageyev \& S. Miller (Eds.), Vygotsky's educational theory in cultural context (pp. 39-64). New York: Cambridge University Press.

Cole, M., \& Engestrom, Y. (1993). A cultural-historical approach to distributed cognition. In G. Salomon (Ed.), Distributed cognitions: Psychological and educa-tional considerations (pp. 1-46). New York: Cambridge University Press.

Engestrom, Y. (1987). Learning by expanding: An activity-theoretical approach to developmental research. Helsinki, Fin.: Orienta-Konsultit.

Engestrom, Y. (2001). Expansive learning at work: Toward an activity-theoretical reconceptualization. Journal of Education and Work, 14(1), 133-156.

Erickson, F. (1990). Qualitative methods. In R. Linn \& F. Erickson (Eds.), Research in teaching and learning (pp. 75-194). New York: Macmillan.

Goncu, A., \& Becker, J. (1992). Some contributions of a Vygotskian approach to early education. International Journal of Cognitive Education and Mediated Learning, 2(2), 147-153.

Grimes, S. M. (2010). The digital child at play: How technological, political and commercial rule systems shape children's play in virtual worlds. Unpublished doctoral dissertation, Simon Fraser University, Burnaby, BC (Canada). Retrieved from http://prezi.com/xecvrbdrqo3n/digital-child-atplay-defense/

Marsh, J. (2010). Young children's play in online virtual worlds. Journal of Early Childhood Research, 8 (1), 23-39.

Marsh, J. (2011). Young children's literacy practices in a virtual world: Establishing an online "interaction order." Reading Research Quarterly, 46(2), 101-118.

Matusov, E., \& Hayes, R. (2000). Sociocultural critique of Piaget and Vygotsky. New Ideas in Psychology, 18, 215-239.

Prensky, M. (2006). Don't bother me, mom, I'm learning. St. Paul, MN: Paragon House.

Rowsell, J., \& Burke, A. (2009). Reading by design: Two case studies of digital reading practices. Journal of Adolescent and Adult Literacy, 53(2), 106-118.

Stephens, C. L., \& Ballast, K. H. (2010). Using technology to improve adolescent writing. Boston: Pearson. 
Trespalacios, J., Chamberlin, B., \& Gallagher, R. R. (2011). Collaboration, engagement \& fun: How youth preferences in video gaming can inform 21st century education. TechTrends, 55(6), 49-54.

United States Census Bureau. (2010). Reported Internet usage for individuals 3 years and older, by selected characteristics. Retrieved from: http://www.census.gov/hhes/computer/publications/2010.html

Vygotsky, L. S. (1978). Mind in society: The development of higher psychological processes, $14^{\text {th }}$ ed. London: Harvard University Press.

Vygotsky, L. S. (1987). Thinking and speech. In R. W. Rieber \& A. S. Carton (Eds.), The collected works of L. S. Vygotsky. Vol. 1. Problems of general psychology (pp. 39-285). New York: Plenum Press.

Warschauer, M. (2008). Whither the digital divide? In D. L. Kleinman, K. A. CloudHansen, C. Matta, and J. Handesman (Eds.), Controversies in science \& technology: From climate to chromosomes. New Rochelle, NY: Liebert.

Wertsch, J. V. (1991). Voices of the mind: A sociocultural approach to mediated action. Cambridge, MA: Harvard University Press. 